\title{
Cardiac and startle responses to acoustic stimuli in the rat*
}

\author{
DONALD V. CHALMERS \\ Pennsylvania State University, University Park, Pennsylvania 16802 \\ and \\ HOWARD S. HOFFMAN \\ Bryn Mawr College, Bryn Mawr, Pennsylvania 19010
}

\begin{abstract}
Electrocardiograms and behavioral startle were recorded on five rats while they were presented a random series of three acoustic stimulus configurations: (1) a 120-dB burst of random noise, (2) an 80-dB burst, and (3) an 80-dB burst followed $100 \mathrm{msec}$ later by a $120-\mathrm{dB}$ burst. Behavioral results revealed suppression of overt startle to the double-pulse configuration, confirming earlier reports. Heart rate results indicated a predominant acceleratory peak from 20 to 40 beats after all three stimulus configurations.
\end{abstract}

At a psychophysical level, it has been amply demonstrated that the startle response to an intense pulse of noise is attenuated when a weaker signal (which itself does not ordinarily elicit an overt response) precedes a more intense startle-evoking stimulus by a short period of time, e.g., $100 \mathrm{msec}$ (Hoffman \& Searle, 1965 , 1968). Although these demonstrations have included designs that permit hypotheses about the nature of the mechanisms responsible for the obtained response attenuation, no attempt has been made to document any of the direct physiological consequences of the different stimulus configurations. The present research was designed to provide an analysis of one such physiological consequence: the cardiac reaction. In particular, the work examined the cardiac reaction of the rat to an intense startle-eliciting acoustic stimulus and compared it to the cardiac reaction engendered when that same stimulus was preceded by a weaker startle-attenuating pulse of noise.

In addition to its importance for the interpretation of the attenuation phenomenon, information about the accompanying cardiac reaction is relevant to the broad problem of using physiological measures as indices of different modes of central stimulus processing. This possibility was first recognized by Sokolov (1963), who sought to distinguish between orienting and defensive reflexes using vasomotor responses as his primary index for distinction. More recently, Graham and Clifton (1966) have extended Sokolov's theory using heart rate as the critical index. According to these authors, cardiac deceleration is associated with the orienting reflex and stimulus intake, while cardiac acceleration is associated with the defense reflex and the shutting out of

*This research was supported by NSF Grant GB 27932 and NIMH Grant MH 19715, both directed by the second author. Reprints may be obtained from Howard S. Hoffman, Department of Psychology, Bryn Mawr College, Bryn Mawr, Pennsylvania 19010. stimulation. Graham and Clifton noted, however, that a number of investigators in this area have reported biphasic cardiac responses, e.g., initial acceleration followed by deceleration below baseline rates, in studies designed to examine orienting behavior. To explain such results, Graham and Clifton have argued that the initial acceleration is due to startle evoked by the "noisy" stimulus onsets obtained with standard relay programming equipment. In an experiment designed to test this hypothesis, Hatton, Berg, and Graham (1970) varied both acoustic rise time and stimulus intensity, while recording the cardiac responses of human Ss to acoustic stimuli. It was found that relatively intense (90 dB re .0002 dynes $/ \mathrm{cm}^{2}$ ) signals with long rise times $(300 \mathrm{msec})$ produced the cardiac deceleration that is presumably characteristic of the orienting reflex, whereas the same signals with a short rise time ( $<5$ microsec) yielded biphasic responses in which a short period of acceleration was followed by a longer period of deceleration. Although Hatton, Berg, and Graham noted that signals with such short rise times should be capable of eliciting startle (Fleshler, 1965), they did not obtain measures of this response. The present investigation provided those measures and directly related them to the cardiac reaction.

\section{METHOD}

\section{Subjects}

Five experimentally naive male Wistar rats were tested. They were approximately 120 days old at the beginning of the research and were maintained on ad lib food and water throughout the experiment.

\section{Apparatus}

All testing was carried out in an electrically shielded Industrial Acoustics Company sound-attenuating room, Model 1200-A. The basic design of the device used to assess behavioral startle has been described fully by Hoffman and Fleshler (1965). 

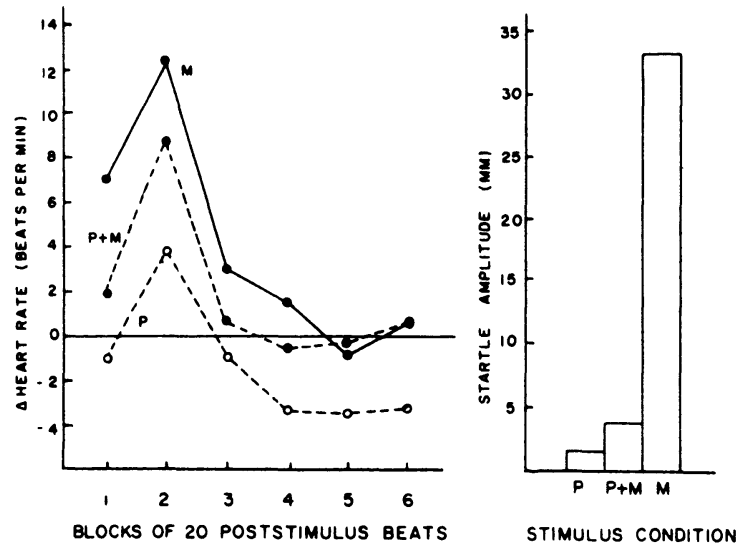

Fig. 1. Cardiac reaction and overt startle response to prepulse only (P), prepulse followed by main-pulse $(\mathrm{P}+\mathrm{M})$, and to main-pulse only (M).

Briefly, it consisted of a small cage $(20 \times 13 \times 15 \mathrm{~cm})$ rigidly supported by a heavily damped Fibreglass springing system. Cage movements were mechanically transmitted to a magnet located in a stationary coil. When the $\mathrm{S}$ made a sudden movement (as during startle), an electrical current was generated in the coil. This current was amplified, rectified, and passed to a recording milliameter.

Discrete acoustic stimuli were generated by feeding the output of a General Radio random-noise generator through a Grason-Stadler electronic switch, which was controlled by a Grason-Stadler interval timer to allow precise control over the duration and rise-decay time of the stimuli. Final amplification was achieved by passing the output of the electronic. switch through one channel of a Crown $300-\mathrm{W}$ power amplifier. Stimuli were delivered to $\mathrm{Ss}$ through a $20.3-\mathrm{cm}$ midrange speaker, mounted $30 \mathrm{~cm}$ from the S's cage. Continuous background noise from a second random-noise generator was fed through the second channel of the Crown amplifier and delivered through another $20.3-\mathrm{cm}$ midrange speaker, mounted $1 \mathrm{~m}$ from the S's cage. The intensity of the background noise measured inside the S's cage was $70 \mathrm{~dB}$ (re .0002 dynes $/ \mathrm{cm}^{2}$ ).

The method used for electrocardiogram (EKG) recording was similar to that described by Word, Stern, Sines, and McDonald (1959). Recording electrodes were made up of two strands of No. 27 wire twisted together and implanted in the S's skin. The electrodes were inserted on the dorsal midline, one just posterior to the shoulder blades and one just anterior to the rear legs, under light $(20 \mathrm{mg} / \mathrm{kg})$ Nembutal anesthesia, with the ends twisted together to form a small loop. Small alligator clips were used to attach leads to the electrodes for recording. The EKG signal was first amplified within the sound-attenuating room and then passed along shielded cable to a Brush Mark II recorder, located just outside the room.

\section{Procedure}

Surgical procedures were carried out 1 week prior to any formal testing. Ss were allowed two 1-h adaptation periods in the experimental cage. During the second of these adaptation periods, the recording leads were attached, and a check was made on the quality of the EKG signal.

There were 4 days of actual testing, with a 3- to 5-day rest between each of the experimental days. Each experimental day began with a 10-min adaptation period, during which Ss were exposed only to the 70-dB background noise. Following the adaptation period, Ss were presented with a total of 18 stimuli, six random permutations of the three stimulus configurations:
(1) prepulse only, an $80-\mathrm{dB}$ burst of broadband random noise; (2) main pulse only, a 120-dB burst of noise; and (3) prepulse plus main-pulse, i.e., a prepulse followed by a main-pulse, with a 100 -msec delay between prepulse onset and main-pulse onset. The intensity of all stimuli was measured inside the S's cage (re $.0002 \mathrm{dynes} / \mathrm{cm}^{2}$ ), and the stimulus duration in all cases was $20 \mathrm{msec}$, with a rise-decay time of $0.1 \mathrm{msec}$. Intertrial intervals were determined by randomizing the permutations of three possible intervals: 2,3 , and $4 \mathrm{~min}$.

\section{Quantification of Data}

Heart rate was measured according to the method described by Word, Stern, Sines, and McDonald (1959). The EKG record was divided into a 20-beat interval prior to stimulation and into six such intervals after stimulation had been presented. For those stimulus configurations involving a main-pulse, the reference point for the measurement was the onset of the intense signal. For stimuli that consisted of a prepulse only, the reference point was the onset of the prepulse. The time required for each block of 20 beats was determined, and this measure was then converted into average beats per minute. Finally, heart rate change scores were obtained by subtracting prestimulation heart rate from poststimulation heart rate over each of the six poststimulation intervals.

\section{RESULTS}

The right side of Fig. 1 shows the mean startle amplitude (in millimeters of pen deflection) across the 24 presentations of each stimulus configuration (i.e., six presentations of a given stimulus on each of 4 days). A repeated-measures analysis of variance revealed a significant effect of stimulus configuration $(F=66.4$, $\mathrm{df}=2 / 8, \mathrm{p}<.01$ ), and a Newman-Keuls test of the individual comparisons revealed that, although the prepulse only and the prepulse plus main-pulse did not differ from each other, each was significantly different from the main-pulse alone $(p<.01)$. This is in complete agreement with earlier behavioral results reported by Hoffman and Searle $(1965,1968)$ and reflects the strong inhibitory effect of the prepulse.

The heart rate data are summarized on the left side of Fig. 1. Each point represents the average change in heart rate over the basal prestimulus level across the 24 presentations of each stimulus configuration. The average basal heart rate was 347 beats per minute, and this rate did not differ significantly among the three stimulus configurations.

The most prominent feature of the heart rate changes was that all three stimulus configurations evoked an acceleratory response that peaked during the second poststimulus measurement level. The amplitude of this acceleratory peak on a given trial was not, however, associated with the amplitude of the overt startle evoked on that trial. The correlation coefficient was only $r=0.13(p>.05)$ when calculated across all Ss and trials. Following the acceleratory peak, heart rate declined in all conditions, but only the response to the prepulse alone was truly biphasic, i.e., heart rate actually decreased below prestimulus level. A repeated-measures analysis of variance of the heart rate data yielded a 
significant effect of measurement periods $(F=7.26$, $\mathrm{df}=5 / 20, \mathrm{p}<.05)$, a significant effect of stimulus configuration $(\mathrm{F}=6.73, \mathrm{df}=2 / 8, \mathrm{p}<.05)$, and $a$ significant interaction between these two factors $(F=2.52, \quad d f=10 / 40, p<.05)$. Newman-Keuls tests were used to assess the statistical significance of the differences among the three stimulus configurations. Those tests revealed that the overall level of the heart rate response to each stimulus configuration differed reliably from the levels of the responses to the other two $(p<.05$ in each case).

\section{DISCUSSION}

These findings appear to be in general agreement with the theoretical position of Graham and Clifton. In the present study, all of the stimuli had abrupt onsets. According to Graham and Clifton, such stimuli, if sufficiently intense, should produce a defense reaction accompanied by cardiac acceleration. The main-pulse alone and the prepulse plus main-pulse both incorporated an intense signal (the main-pulse), and both produced the cardiac acceleration that is thought to characterize the defense reaction. The prepulse alone also had an abrupt onset and, although it was too weak to produce startle reliably, the cardiac reaction nonetheless exhibited an initial acceleratory component. This, however, was followed by a strong deceleratory component, a finding that again agrees with the interpretation of Graham and Clifton. As noted earlier, these authors suggest that biphasic responses are characteristic of weak signals with abrupt onsets. Presumably, such responses reflect the occurrence of a weak defense reaction followed by an orienting reaction.

Of special interest here is the finding that, in addition to inhibiting overt startle, the addition of a prepulse to a main-pulse produced reliable (though incomplete) inhibition of the cardiac reaction. While this finding plus the lack of correlation between the amplitude of startle and the amplitude of cardiac acceleration suggests a fair amount of disassociation between the cardiac reaction and overt startle, it does not necessarily imply that the two behaviors are disassociated at all levels. In particular, it seems possible to account for these data by assuming that both reactions depend upon a common central process, but the threshold for its expression via a cardiac reaction is lower than the threshold for its expression via an overt startle response. (That the prepulse alone consistently evoked cardiac acceleration, while failing to evoke overt startle, is consistent with this proposition.) Under such circumstances, presentation of a weak pulse prior to an intense startle-evoking stimulus might inhibit the central process but, since the threshold for the overt expression of the two reactions differs, only the response with the lower threshold would survive. In short, the skeletal response might be largely abolished by a prepulse, whereas the cardiac reaction would be only slightly diminished. As revealed in Fig. 1, this is what appears to have happened in the present study.

\section{REFERENCES}

Fleshler, M. Adequate acoustic stimulus for startle reaction in the rat. Journal of Comparative \& Physiological Psychology, 1965, 60, 200-207.

Graham, F. K., \& Clifton, R. K. Heart rate change as a component of the orienting response. Psychological Bulletin, 1966, 65, 305-320.

Hatton, H. M., Berg, W. K., \& Graham, F. K. Effects of acoustic rise time on heart rate response. Psychonomic Science, 1970, 19, 101-103.

Hoffman, H. S., \& Fleshler, M. An apparatus for the measurement of the startle-response in the rat. American Journal of Psychology, 1964, 77, 307-308.

Hoffman, H. S., \& Searle, J. L. Acoustic variables in the modification of startle reaction in the rat. Journal of Comparative \& Physiological Psychology, 1965, 60, 52-58.

Hoffman, H. S., \& Searle, J. L. Acoustic and temporal factors in the evocation of startle. Journal of the Acoustical Society of America, 1968, 43, 269-282.

Sokolov, E. N. Perception and the conditioned reflex. New York: Macmillan, 1963.

Word, T. J., Stern, J. S., Sines, J. O., \& McDonald, D. G. The cardiac response of the albino rat: A preliminary report. Psychophysiological Newsletter, 1959, 5, 11-15.

(Received for publication July 12, 1972; revision received August 24, 1972.) 